\title{
Thoracic endovascular aortic repair with left subclavian artery coverage without prophylactic revascularisation-early and midterm results
}

\author{
J. Wojciechowski • L. Znaniecki • K. Bury • J. Rogowski
}

Received: 4 May 2013 / Accepted: 23 March 2014 /Published online: 26 April 2014

(C) The Author(s) 2014. This article is published with open access at Springerlink.com

\begin{abstract}
Background The management of the left subclavian artery when coverage is necessary during thoracic aorta endografting remains a matter of debate.

Materials and methods A retrospective analysis of a singlecentre experience with thoracic endovascular aorta repair (TEVAR) was performed. Between April 2004 and October 2012, 125 cases of TEVAR were performed. The analysis focused on patients who required coverage of the left subclavian artery (LSA). We analysed mortality and morbidity with special attention to the rates of cerebrovascular accidents (CVAs) and spinal cord ischaemia (SCI) in the early and midterm.

Results Of the 125 patients, 53 (42\%, group A) required an intentional coverage of the LSA to obtain an adequate proximal seal for the endograft; the remaining patients constituted group B. None of the patients in group A had protective LSA revascularisation prior to TEVAR. The primary technical success rate was 79.2 vs. $90.3 \%$ (group A vs. group $\mathrm{B}, p=0.08$ ), and the primary clinical success rate was 77.4 vs. $82 \%$ (group A vs. group $\mathrm{B}, p=0.53$ ). The 30 -day mortality rate was 11.3 vs. $11.1 \%$ (group A vs. group $\mathrm{B}, p=0.97$ ). The 30-day morbidity was 7.5 vs. $13.9 \%$ (group A vs. group $\mathrm{B}, p=0.4$ ). CVA occurred in $1.9 \%$ of group A patients, compared to $1.4 \%$ of patients from group B ( $p=0.82)$. The $\mathrm{SCI}$ incidence rate was 0 vs. $1.4 \%(p=0.39)$. The mean follow-up of group A was 24.1 months (range 2-64.6 months, $\mathrm{SD}=19$ ). Additionally, the 1-year estimated survival was $85.5 \%$, and the 3-year estimated survival was $78 \%$. There were no midterm CVAs; one event of SCI occurred in the seventh postoperative month in group A.
\end{abstract}

J. Wojciechowski $\cdot$ L. Znaniecki $(\bowtie) \cdot$ K. Bury $\cdot$ J. Rogowski Department of Cardiac and Vascular Surgery, Medical University of Gdansk, ul. Debinki 7, 80-211 Gdansk, Poland

e-mail: 1.znaniecki@gmail.com
Conclusion Our analysis, although retrospective and based on one institution experience, shows a realistic population of TEVAR patients. We prove that TEVAR with coverage of LSA origin can be accomplished with minimal neurological morbidity in this patient population. The study shows that LSA revascularisation is not mandatory before endograft deployment, especially in emergency settings. We also prove that although zone 2 TEVAR extends the proximal landing zone, it does not prevent type IA endoleaks from appearing. A multicentre randomised control trial with higher number of patients is necessary for proper, robust conclusion to be established.

Keywords TEVAR - Thoracic endovascular aortic repair . Aorta $\cdot$ Aneurysm $\cdot$ Dissection $\cdot$ Left subclavian artery

\section{Introduction}

Thoracic endovascular aortic repair (TEVAR) has rapidly become an accepted treatment option for numerous aortic pathologies [1-4]. An important requirement for successful endografting is confirming the health of the aorta in the landing zone where the graft is deployed. Left subclavian artery (LSA) coverage is necessary to achieve the proximal seal in up to $50 \%$ of patients treated with TEVAR [5-9]. The management of LSA revascularisation in this cohort of patients remains a matter of debate. A 2009 consensus from the Society of Vascular Surgery described the quality of the existing evidence on the performance of subclavian revascularisation in patients undergoing TEVAR as low (2C) [10]. A 2011 literature review from the European Association for Cardio-Thoracic Surgery, which resulted in the formulation of recommendation of prophylactic LSA revascularisation in elective patients, was based on numerous and heterogeneous series with small samples of patients [11]. Studies in support of 
routine preoperative LSA revascularisation show that the coverage of the LSA during TEVAR is associated with an increased risk of stroke, paraplegia and arm ischaemia. Other studies have shown that coverage of the LSA without prophylactic revascularisation is not associated with increased morbidity, supporting those results promoting selective LSA revascularisation during TEVAR [7, 12-14]. In this study, we analysed the consequences of intentional LSA coverage during TEVAR with special attention to the development of neurologic complications in a real life, non-selected ("all comers") population.

\section{Materials and methods}

Between April 2004 and October of 2012, 125 TEVAR procedures were performed in our department. Of those, $42 \%$ $(n=53)$ required stent-graft $(\mathrm{S}-\mathrm{G})$ deployment with intentional coverage of the origin of the left subclavian artery (Ishimaru zones 0-2 [15], group A), and this population constituted our studied group. The remaining patients had no coverage of the LSA (Ishimaru zones 3 and 4 [15], group B). We retrospectively reviewed a prospectively maintained database, medical records and imaging studies. Patients' characteristics are listed in Table 1. The outcome measures evaluated included the rate of cerebrovascular accident (CVA), spinal cord ischaemia (SCI), and mortality and overall morbidity in early, as well as midterm observations. CVA was defined as any stroke or transient ischemic event, regardless of the extent of recovery. SCI was defined as any transient or permanent paralysis or paresis at any time after TEVAR.

Preoperative planning was performed on Apple MacBook Pro systems with OsiriX DICOM Viewer version 3.9.4 (Pixmeo Sàrl, Bernex, Switzerland). The decision on the LSA coverage was based on preoperative contrast enhanced computed tomography (CTA) of the neck and thorax, evaluating the anatomy of the thoracic aorta, aortic arch and carotid and

Table 1 Patients' demographics

\begin{tabular}{llll}
\hline Variable & $\begin{array}{l}\text { Group A (\%) } \\
n=53\end{array}$ & $\begin{array}{l}\text { Group B (\%) } \\
n=72\end{array}$ & $p$ value \\
\hline Age, median \pm SD years & $61 \pm 15.2$ & $72 \pm 14.4$ & 0.06 \\
Male gender & $44(83 \%)$ & $52(72.2 \%)$ & 0.16 \\
CAD & $6(11.3 \%)$ & $13(18.1 \%)$ & 0.30 \\
Prior MI & $1(1.9 \%)$ & $8(11.1 \%)$ & 0.10 \\
Diabetes & $5(9.4 \%)$ & $9(12.5 \%)$ & 0.59 \\
Renal failure & $0(0 \%)$ & $6(8.3 \%)$ & 0.32 \\
Hypertension & $39(73.6 \%)$ & $45(62.5 \%)$ & 0.19 \\
Prior AAA open repair & $5(9.4 \%)$ & $7(9.7 \%)$ & 0.95
\end{tabular}

$S D$ standard deviation, $C A D$ coronary artery disease, $M I$ myocardial infarction, $A A A$ abdominal aortic aneurysm vertebral arteries. The anatomy of the circle of Willis was not routinely assessed. To further evaluate the cerebrovascular anatomy, doubtful elective patients in this subgroup underwent preoperative carotid and vertebral artery duplex Doppler ultrasonography. Three-dimensional MPR image reconstructions were performed to obtain centreline measurements of the aortic lumen. In patients who did not undergo supplemental preoperative imaging, the arch vessel anatomy was evaluated intraoperatively before S-G deployment. In elective cases, a proximal landing zone of $\geq 15$-mm length was required. In emergency cases, however, $\mathrm{a} \geq 10$-mm proximal aortic "neck" was deemed suitable. In cases with shorter necks, the decision to cover the LSA was made. To classify the proximal landing zones, the aortic arch map with zones $0-4$ by Ishimaru [15] was applied. In cases that required zone 0 TEVAR, patients would initially attain aortic debranching by the implantation of a bifurcated bypass from the ascending aorta to the brachiocephalic trunk and LCCA; later, during the same procedure, the $\mathrm{S}-\mathrm{G}$ would be deployed in zone 0 . Patients requiring zone 1 deployment underwent right-to-left carotidcarotid bypass procedures using an $8-\mathrm{mm}$ Dacron graft.

We practice the strategy of conditional prophylactic revascularisation of the LSA in patients with patent LIMALAD bypass, dominant left vertebral or hypoplastic right vertebral artery, patent left arm dialysis fistula or axillo-femoral bypass graft. Additionally, intraoperative indications for LSA revascularisation include symptoms of acute left arm ischaemia.

From 2004 to 2009, our endovascular team consisted of a vascular surgeon and an interventional radiologist, and the procedures were performed in an interventional radiology suite. From 2009 to the present, a team of vascular and cardiac surgeons has been performing elective cases using a mobile Carm (Siemens ARCADIS Avantic), while emergency cases are performed in an interventional radiology suite using an Siemens Artis zee C-arm (vascular surgeon and radiologist) unless aortic debranching is required (in those cases, the procedures are performed in the surgical theatre with the use of mobile C-arm).

In total, $63 \%$ of procedures were performed under general anaesthesia, and $37 \%$ were performed using loco-regional anaesthesia and sedation. Rapid pacing was used in one patient during S-G deployment in the critical landing zone.

Mean procedure time was 119 min ranging from 60 to $210 \mathrm{~min}$.

No intraoperative neurological monitoring was conducted. Post-operative neurological assessments occurred every $2 \mathrm{~h}$ in the first eight post-operative hours and then every $4 \mathrm{~h}$ in uncomplicated cases (by either treating or on-call surgeon or anaesthesiologist). Our institution practices a policy of selective spinal drainage; this was reserved for complicated cases only. In cases of SCI, spinal drainage and augmentation of the mean arterial pressure would be utilised. 
The stent grafts used are described in detail in Table 2.

Thoracic stent-graft delivery was approached through the common femoral artery in 118 patients, through the common iliac artery in 4 and through abdominal aorta in 3 patients. In these cases, an 8-mm vascular prosthesis was implanted end to side toward either the right common iliac artery or abdominal aorta and was then used as a technical conduit.

Patient follow-up included history, physical examination and CTA. Patients were typically seen at 1, 3, 6 and 12 months and annually thereafter. In specific conditions, follow-up was adjusted accordingly. During follow-up, the patients were specifically assessed for neurologic changes and evidence of arm ischaemia. CTA was used to assess the durability of the stent-graft repair.

Categorical variables were analysed using a nonparametric $\chi^{2}$ test. In instances where the $\chi^{2}$ test was unreliable due to a small sample size, the Fisher exact method was employed to test the association. Continuous variables were presented as medians, and they did not show a Gaussian distribution. Survival was analysed with the KaplanMeier and life-table analysis methods. All statistical analyses were performed using Statistica 7.1 software (StatSoft Inc., Tulsa, OK).

Primary technical success was defined as the successful introduction and deployment of the device in the absence of surgical conversion, death in $\leq 24 \mathrm{~h}$ and type I or III endoleaks, or graft obstruction [16].

Primary clinical success was defined as the successful deployment of the endovascular device at the intended location without death as a result of aneurysm-related treatment, type I or III endoleaks, graft infection, thrombosis, aneurysm expansion, aneurysm rupture or conversion to open repair [16].

\section{Results}

\section{Indications}

There were 76 elective (25 in group A and 51 in group B) and 49 emergency (28 in group A and 21 in group

Table 2 Stent grafts used

\begin{tabular}{lll}
\hline Stent graft & $\begin{array}{l}\text { Group A } \\
(\%)\end{array}$ & $\begin{array}{l}\text { Group B } \\
(\%)\end{array}$ \\
\hline $\begin{array}{l}\text { Zenith TX2 (Cook Inc., } \\
\text { Bloomington, IN) }\end{array}$ & $34(64.1 \%)$ & $45(62.5 \%)$ \\
$\begin{array}{l}\text { E-vita Thoracic (JOTEC GmBH, } \\
\text { Hechingen, Germany) }\end{array}$ & $11(20.7 \%)$ & $19(26.4 \%)$ \\
$\begin{array}{l}\text { Valiant (Medtronic, Minneapolis, MN) } \\
\text { Relay (Bolton Medical, Sunrise, FL) }\end{array}$ & $4(0.7 \%)$ & $5(6.9 \%)$ \\
\hline
\end{tabular}

B) procedures. Among these, 110 were primary and 15 were secondary procedures. The indications for treatment are listed in Table 3. No patient who required zone 2 coverage had absolute indications for LSA revascularisation, and therefore, no preoperative revascularisation of the LSA was performed.

Proximal landing zone

There was one $(1.9 \%)$ deployment in zone 0 . The proximal landing zone was zone 1 in 3 patients $(5.8 \%)$ and zone 2 in 48 patients $(92.3 \%)$. In the remaining cases, stent grafts were landed in zones either 3 or 4 .

The primary technical success rate in group A was $79.2 \%(n=42)$. Assisted primary success was obtained in one patient $(1.9 \%)$ who required additional procedure during the same hospital stay, with proximal S-G deployment, due to a large type IA endoleak. Secondary success was obtained in two patients $(3.8 \%)$. The first of these was a female patient treated on an emergency basis for aortic transection due to vehicle trauma. She required additional subclavian-carotid transposition and forearm fasciotomy for acute left arm ischaemia, which developed after emergency TEVAR with LSA coverage (procedure performed in hypovolemic shock). Another patient was also treated on emergency basis (complicated acute type B aortic dissection). In this case, where zone 2 deployment was intended, post-deployment aortography revealed the coverage of LCCA origin (accidental zone 1 deployment). The patient was taken to the operating theatre, and RCCA to LCCA bypass was performed immediately. However, he developed stroke, and mild hemiplegia was present when the patient woke up after the procedure and on the day of discharge from the hospital. One patient had type III endoleak. Thus, the overall technical success rate in group A was $84.9 \%(n=45)$.

In group A, five patients had type IA endoleaks on completion angiography. In three cases, the endoleaks were minor, and decision on conservative treatment was made; these endoleaks had sealed upon follow-up observation and were absent on last follow-up CTA observations, taken on the 10th, 18th and 26th months after the procedure, respectively. In one case, a minor endoleak sealed upon follow-up and was absent on the last CTA control, performed on the 28th month postprocedure. Further follow-up contact with the patient was lost for 1.5 years, but then, he was admitted to our service in an emergency setting with rapidly enlarging, symptomatic thoracic aortic aneurysm (TAA) due to S-G migration and recurrence of type IA endoleak. He was taken to surgery right away, and debranching of the aortic arch by implantation of bifurcated prosthesis from 
Table 3 Indications for treatment

\begin{tabular}{|c|c|c|c|c|c|c|c|}
\hline \multirow[t]{2}{*}{ Indication } & \multicolumn{3}{|c|}{ Group A $(n=53)$} & \multicolumn{3}{|c|}{ Group B $(n=72)$} & \multirow[t]{2}{*}{$p$ value } \\
\hline & $\begin{array}{l}\text { Elective, } \\
\text { no. }(\%)\end{array}$ & $\begin{array}{l}\text { Emergency, } \\
\text { no. }(\%)\end{array}$ & All, no. (\%) & $\begin{array}{l}\text { Elective, } \\
\text { no. }(\%)\end{array}$ & $\begin{array}{l}\text { Emergency, } \\
\text { no. }(\%)\end{array}$ & All, no. (\%) & \\
\hline \multirow{4}{*}{$\begin{array}{l}\text { TAA (mean diameter } 75 \mathrm{~mm} \text {, } \\
\text { range } 53-110 \mathrm{~mm} \text { ) }\end{array}$} & $25(47.2 \%)$ & $28(52.8 \%)$ & & $51(70.8 \%)$ & $21(29.2 \%)$ & & 0.007 \\
\hline & $18(34 \%)$ & & & $44(61.1 \%)$ & & & 0.0027 \\
\hline & & $5(9.4 \%)$ & & & 6 (3 rTAA) $(8.3 \%)$ & & 0.83 \\
\hline & & & $23(43.4 \%)$ & & & $53(73.6 \%)$ & 0.0006 \\
\hline Complicated type B dissection & & $16(30.2 \%)$ & $16(30.2 \%)$ & & $8(11.1 \%)$ & $8(11.1 \%)$ & 0.008 \\
\hline TAT & & $7(13.2 \%)$ & $7(13.2 \%)$ & & $4(5.6 \%)$ & $4(5.6 \%)$ & 0.24 \\
\hline Pseudoaneurysm & $6(11.3 \%)$ & & $6(11.3 \%)$ & $5(6.9 \%)$ & & $5(6.9 \%)$ & 0.39 \\
\hline Aortic ulcer & $1(1.9 \%)$ & & $1(1.9 \%)$ & $2(2.8 \%)$ & & $2(2.8 \%)$ & 0.78 \\
\hline
\end{tabular}

$T A A$ thoracic aorta aneurysm, TAT thoracic aorta transection

ascending aorta to brachiocephalic trunk and LCCA was performed. During the deployment of the proximal extension S-G element in zone 0, the aneurysm ruptured to the left pleural cavity, and patient died intraoperatively. The last patient had a persistent IA endoleak on angio-CT 20 months after the procedure but refused another surgery. The aneurysm enlargement to $74 \mathrm{~mm}$ was observed, and the patient is still under ambulatory surveillance. The initial rate of type IA endoleak was $9.4 \%(n=5)$.

The primary technical success rate in group B was $90.3 \%$ $(n=65)$.

Three type IA endoleaks were observed on completion angiography in group B. Conservative management was used in two cases; the first patient refused secondary procedure - at 2.5 months, significant aneurysm enlargement and rupture were observed with subsequent death of the patient. In the other case, the endoleak was minor and no aorta-related MAE was observed. The third patient had secondary procedure with LSA coverage after 14 months with good clinical result (no further endoleaks). The initial rate of type IA endoleaks was $4.2 \%(n=3)$ in group B.

There were also three type IB endoleaks $(4.2 \%, n=$ $3)$. In one case, type IB endoleak was observed in a patient treated for ruptured TAA, the patient died on post-operative day 1 in symptoms of hypovolemic shock. The remaining two patients had secondary procedures with distal S-G extensions; in both cases, the treatment was successful, with complete resolution of type IB endoleaks.

In one case, intraprocedural distal migration of S-G occurred, SMA origin was covered with the S-G and open extraction of S-G was performed; the patient died on the first post-operative day.

Details are listed in Table 4.
Number of grafts used

In group A, 26 patients required only one element, while in 13 patients, two stent-graft elements were used to cover the entire pathology. In 18 cases, the graft length was higher than $200 \mathrm{~mm}$. Median was $205 \mathrm{~mm}$ (min $134 \mathrm{~mm}$, max $332 \mathrm{~mm}$, standard deviation $\pm 55 \mathrm{~mm}$ ).

In group B, 40 patients were treated with one stent-graft element; in 23 patients, two elements were used; and in two cases, $3 \mathrm{~S}-\mathrm{G}$ elements were necessary to treat the entire aortic

Table 4 Type IA endoleaks

\begin{tabular}{|c|c|c|}
\hline Patient & $\begin{array}{l}\text { Status of endoleak, } \\
\text { last CTA control }\end{array}$ & Clinical outcome \\
\hline \multicolumn{3}{|c|}{ Group A } \\
\hline 1 & Seal, 26th month & $\begin{array}{l}\text { Death on } 27 \text { th month, urinary } \\
\text { bladder carcinoma }\end{array}$ \\
\hline 2 & Seal, 28th month & $\begin{array}{l}\text { Migration, TAA rupture } \\
\text { on 44th month. Another } \\
\text { S-G deployment, } \\
\text { intraoperative death }\end{array}$ \\
\hline 3 & Sealed & Uneventful \\
\hline 4 & Sealed & Uneventful \\
\hline 5 & $\begin{array}{l}\text { Another S-G placement } \\
\text { during same hospital } \\
\text { stay, seal }\end{array}$ & Uneventful \\
\hline 6 & $\begin{array}{l}\text { Persistant IA } \\
\text { endoleak }\end{array}$ & $\begin{array}{l}\text { Aneurysm growth to } 74 \mathrm{~mm} \text {, } \\
\text { patient refuses another } \\
\text { procedure }\end{array}$ \\
\hline \multicolumn{3}{|c|}{ Group B } \\
\hline 1 & No seal & $\begin{array}{l}\text { TAA rupture on 3rd month, } \\
\text { death }\end{array}$ \\
\hline 2 & Seal, 48th month & $\begin{array}{l}\text { Death on 54th month due } \\
\text { to acute pancreatitis }\end{array}$ \\
\hline 3 & Persistant type IA endoleak & Patient refuses surgery \\
\hline
\end{tabular}

$S-G$ stent graft, $T A A$ thoracic aorta aneurysm 
pathology. In 38 cases, the combined length of covered aorta was longer than $200 \mathrm{~mm}$ with a median of $213 \mathrm{~mm}$ (min $127 \mathrm{~mm}$, max $353 \mathrm{~mm}$, standard deviation $\pm 73 \mathrm{~mm}$ ).

Results based on stent-graft types are described in Table 5.

In other cases, a retrospective review of the patients' notes would not allow us to establish the graft length or number of elements used.

\section{Type II endoleaks}

There were no type II endoleaks originating from covered LSA in group A. There was two type II endoleaks in group B.

Primary clinical success

The 30-day mortality rate was $11.3 \%$ in group A and $11.1 \%$ in group B. Therefore, the primary clinical success rate was $77.4 \%$ $(n=41)$ in group A and $82 \%(n=59)$ in group B. A detailed description of early mortality may be found in Table 6 .

The overall 30-day morbidity was $7.5 \%(n=4)$ in group A and $13.9 \%(n=10)$ in group B. No access site complications developed in group $\mathrm{A}$, and there were five access related complications in group B.

The 30-day mortality and morbidity are listed in Table 7.

Early neurologic complications

One stroke arose during the early observation period (stroke rate of $1.9 \%$ ) in group A and one stroke was observed in group B $(1.4 \%)$. No transient or permanent paraplegia had developed in group $\mathrm{A}$ in the 30-day observation, compared to one incident of paraparesis in group B (transient-complete resolution was observed on follow-up visit on the third month). In comparison with the group with LSA left uncovered, the experimental group showed no statistical significance in terms of
CVA ( 1.9 vs. $1.4 \%, p=0.82)$ or SCI incidence rate $(0$ vs. $1.4 \%, p=0.39)$.

Midterm clinical success

The mean follow-up of group A was 24.1 months (range 2-64.6 months, SD $=19$ months). The 1-year estimated survival was $87.7 \%$ (standard error $=0.047$ ) for group A vs. $81.7 \%$ (standard error $=0.055$ ) for group $\mathrm{B}(p=0.64)$; the 3 -year estimated survival was $82.3 \%$ (standard error $=0.069$ ) in the studied group and $81.7 \%$ (standard error $=0.055)$ in group B $(p=$ 0.65 ) (Fig. 1). The rate of late IA endoleaks in the studied group during the follow-up period was $9.4 \%$. Three type IA leaks (at 16, 20 and 43 months, respectively) were detected. One patient required zone 1 TEVAR after RCCA to LCCA bypass, and a follow-up CTA revealed sealed endoleak. The two other patients are on waiting lists for proximal extension procedures. Two secondary type IB leaks (6 and 18 months) were detected. Both were treated with secondary interventions with technical success. No type II leaks were found. No patients required open conversion.

In one patient, late paraplegia occurred (seventh month). He was treated for TAA with a history of prior AAA treatment with straight tube open repair. The MRI of his spine had revealed an ischemic focus on the T6T8 level. In the follow-up CTA, a secondary IA endoleak was found in this patient (before paraplegia occurred).

Four cases of left arm ischaemia developed, and all were managed conservatively, with no need for revascularisation due to mild symptoms.

Four patients developed subclavian steal syndrome in midterm, with only one case becoming so profound that it required LSA to LCCA transposition. The effect of this procedure was good, with a complete resolution of symptoms and uneventful post-operative course.

Table 5 Results based on stent-graft type

\begin{tabular}{|c|c|c|c|c|c|c|c|c|c|c|}
\hline & \multicolumn{5}{|c|}{ Group A } & \multicolumn{5}{|c|}{ Group B } \\
\hline & Death & $\begin{array}{l}\text { Type IA } \\
\text { endoleak }\end{array}$ & $\begin{array}{l}\text { Type IB } \\
\text { endoleak }\end{array}$ & CVA & SSS & Death & $\begin{array}{l}\text { Type IA } \\
\text { endoleak }\end{array}$ & $\begin{array}{l}\text { Type IB } \\
\text { endoleak }\end{array}$ & CVA & SCI \\
\hline Zenith TX2 (Cook Inc., Bloomington, IN) & 5 & & & & 1 & 5 & 2 & 3 & 1 & \\
\hline E-vita Thoracic (JOTEC GmBH, Hechingen, Germany) & & 2 & & & & 3 & 1 & & & 1 \\
\hline Relay (Bolton Medical, Sunrise, FL) & 1 & 2 & & & & & & & & \\
\hline Valiant (Medtronic, Minneapolis, MN) & & 1 & & & & & & & & \\
\hline Combined & 6 & 5 & & & 1 & 8 & 3 & 3 & 1 & 1 \\
\hline
\end{tabular}

CVA cerebrovascular accident, $S S S$ subclavian steal syndrome, SCI spinal cord ischaemia 
Table 6 Detailed 30-day mortality
$T A A$ thoracic aortic aneurysm, $M O F$ multiorgan failure, $M I$ myocardial infarction, TAT thoracic aorta transection, $P E$ pulmonary embolism

\begin{tabular}{clll}
\hline Patient & Post-op day & Indications & Cause of death \\
\hline $\begin{array}{c}\text { Group A } \\
1\end{array}$ & $24=6,11.3 \%)$ & & \\
& & TAA & $\begin{array}{c}\text { MOF after MI with circulatory } \\
\text { arrest on post-op day } 4\end{array}$ \\
2 & Intraoperative & Ruptured TAA & Hypovolemic shock \\
3 & 23 & TAT & MOF \\
4 & 21 & Complicated type B dissection & MOF \\
5 & 0 & Ruptured TAA & Hypovolemic shock, MOF \\
6 & 17 & TAT, multitrauma & PE \\
Group B $(n=8,11.1 \%)$ & & Retrograde type A dissection \\
1 & 10 & Complicated type B dissection & MI \\
2 & 4 & TAA & Access site injury \\
3 & 1 & TAA & Hypovolemic shock \\
4 & 1 & Ruptured TAA & MOF \\
5 & 3 & Complicated type B dissection & Intraprocedural SMA origin \\
6 & 1 & TAA & occlusion, S-G extraction, MOF \\
7 & 10 & TAA & MOF \\
8 & 6 & Symptomatic TAA & MI \\
\hline
\end{tabular}

\section{Discussion}

In up to $50 \%$ of cases of TEVAR, coverage of the LSA is necessary to obtain a seal and to prevent either type IA endoleaks or stent-graft migration [5-9]. In our population, the extension of landing zone to zones $0-2$ by Ishimaru did

Table 7 Thirty-day mortality and morbidity

\begin{tabular}{lll}
\hline Variable & $\begin{array}{l}\text { Group A } \\
(n=53)\end{array}$ & $\begin{array}{l}\text { Group B } \\
(n=72)\end{array}$ \\
\hline Mortality & $6(11.3 \%)$ & $8(11.1 \%)$ \\
MI & 0 & $2(2.8 \%)$ \\
Reverse type A dissection & 0 & $1(1.4 \%)$ \\
Bleeding from access site & 0 & $1(1.4 \%)$ \\
Intraprocedural distal migration, & 0 & $1(1.4 \%)$ \\
$\quad$ SMA occlusion, laparotomy & & \\
and S-G extraction & $4(7.5 \%)$ & $2(2.8 \%)$ \\
MOF & $1(1.9 \%)$ & $1(1.4 \%)$ \\
Hypovolemic shock & $1(1.9 \%)$ & 0 \\
PE & $4(7.5 \%)$ & $10(13.9 \%)$ \\
Morbidity & $1(1.9 \%)$ & $1(1.4 \%)$ \\
Stroke & 0 & $1(1.4 \%)$ \\
Paraplegia & $1(1.9 \%)$ & 0 \\
SSS & $1(1.9 \%)$ & 0 \\
Left arm ischemia & $1(1.9 \%)$ & $3(4.2 \%)$ \\
MI & 0 & $5(6.8 \%)$ \\
Access site complications & & \\
\hline
\end{tabular}

MI myocardial infarction, SMA superior mesenteric artery, $M O F$ multiorgan failure, $P E$ pulmonary embolism, SSS subclavian steal syndrome not completely prevent type IA endoleakage, with a tendency to increased type IA endoleak rate (9.4 vs. $4.2 \%, p=0.41$ ) in this group.

Chimney technique as well as scallop or multilayered prosthesis is an alternative for TEVAR with LSA coverage. These procedures require long-lasting technical preparation so they cannot be used in emergency cases. Another alternative may be the use of multilayered stents - however, nowadays, it delivers a lot of questions and has as many followers as opponents. The effectiveness of these method requires further investigation and trials; it cannot be recommended as a routine approach to this particular pathology [17].

Due to the extensive circulation provided by the LSA, coverage of the LSA can theoretically lead to grave complications, such as spinal cord ischaemia or cerebrovascular incidents, or to usually better tolerated chronic left arm ischaemia or subclavian steal syndrome. Although infrequent, acute upper extremity ischaemia has also been reported in the setting of LSA coverage [18]. However, such risks may be justified, especially in emergency situations in order to prevent mentioned endoleakage. In our population, there was a significant predominance of acute cases in group where LSA origin was covered (52.8 vs. $29.2 \%, p=0.007$ ).

The management of intentional LSA coverage, particularly in elective setting, remains a matter of debate. Reports of a low incidence of left arm ischaemia shifted the pendulum towards the liberal coverage of the LSA as an attractive means of extending proximal landing zone in the early years of TEVAR [19, 20]. This complication, if it occurs, is welltolerated in the vast majority of cases; if necessary, revascularisation may be implemented in an elective setting 
Fig. 1 Kaplan-Meier survival outcomes for patients with and without coverage of LSA with TEVAR

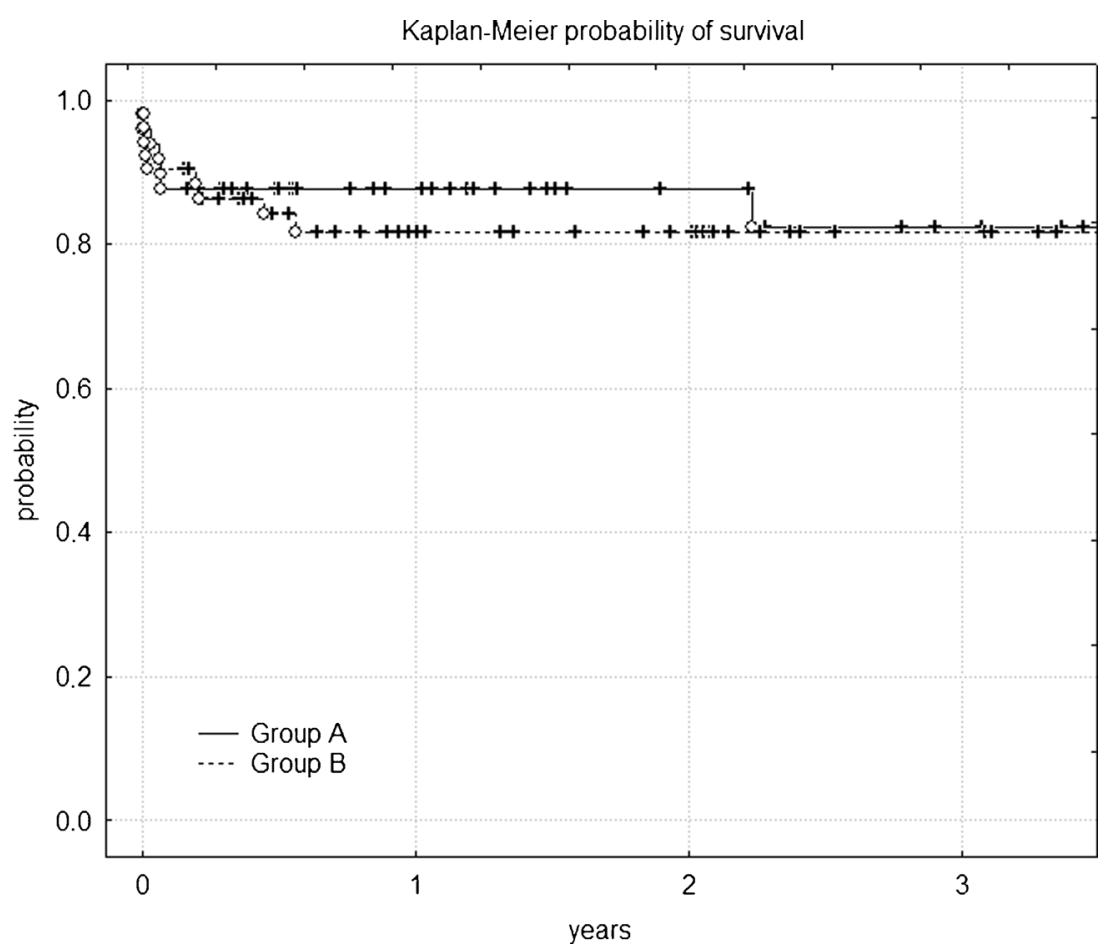

[21]. Still, reports of devastating neurological complications and studies showing an increased incidence of CVA and SCI have been published [22-25], calling for a reconsideration of the liberal LSA coverage policy.

However, the problem of additional risks associated with an extra procedure (LSA revascularisation) remains, and its necessity has been disputed [5, 26-28]. In fact, a high rate of complications, such as stroke (6.6\%) [26] and phrenic nerve injury (12.6\%) [24], has been reported. The most recent analysis published by Madenci et al. revealed a combined CVA and death rate of $5.3 \%$ for isolated LSA reconstructions [29].

There was an attempt to standardise such care, and the Society for Vascular Surgery (SVS) [10] proposed recommendations based on selected trials and meta-analyses. Internally, the SVS recommendation graded the level of evidence as low-2C [10]. In a literature review from 2011, the European Association for Cardio-thoracic Surgery [11] strongly recommends prophylactic LSA revascularisation in elective patients. Still, level I evidence is non-existent.

The aim of this study was to examine the real-life results (tertiary centre providing aortic care to a population of $\sim 2.3$ million) of a selective LSA revascularisation strategy based on absolute indications only.

\section{CVA}

In our group of patients with LSA coverage, one stroke occurred in a patient with an unintentional occlusion of left common carotid artery origin. It appears that this stroke (ischaemic focus in left frontal lobe) was directly related to left common carotid artery occlusion and not to LSA coverage.

However, a significant number of case series and metaanalyses have revealed an increased incidence of CVA in patients with LSA coverage without revascularisation [23, 30-32] and stroke protection by pre-TEVAR restoration of LSA flow [22, 33]. The reason for this is not clear, as many series did not report whether the strokes were in the posterior or anterior circulation. Posterior circulation strokes may indeed result from hypoperfusion caused by LSA coverage. However, anterior circulation strokes are instead often the result of embolisation caused by increased instrumentation in the aortic arch, which often is the case in zone 2 TEVAR procedures. Therefore, LSA coverage may be just an indirect marker of more advanced aortic disease with a higher hazard of embolisation. In fact, several recent papers explaining the reported stroke territory were found to support this theory [34-36]. The embolisation theory may also explain why numerous authors found LSA revascularisation to be ineffective in reducing the stroke rate [7, 12, 13, 23, 35, 37]. Furthermore, recent analysis by Maldonado et al. revealed that LSA revascularisation may even be harmful to certain patients (fourfold higher stroke incidence in females with LSA revascularisation) [14].

In our studied group, there were no other complications than the aforementioned stroke, meaning that neither embolisation strokes from the anterior circulation nor hypoperfusion strokes from the posterior circulation occurred.

Only $34 \%(n=18)$ of our patients were aged older than 70 years, making a relatively young population with a median age of 61 . Secondly, only $43.4 \%$ ( $n=23)$ of patients had thoracic 
aortic aneurysm. Those two facts may indirectly indicate that our population had a low grade of either arch atheroma or thrombus and may explain the low incidence of CVA (an increased chance of CVA due to significant arch atheroma in patients $>70$ years of age was previously postulated [36, 38]).

\section{SCI}

Our population of patients with LSA coverage without prior revascularisation had no SCI after a 30-day observation. This finding is in accordance with those of other studies in which selective LSA revascularisation was performed [7, 12, 13].

Apart from the debate on the influence of LSA coverage on the incidence of SCI, these are the well-known risk factors for paraplegia: coverage of a long segment of the aorta, use of more than three elements of stent grafts during the procedure, prior open abdominal aortic surgery and renal insufficiency [22].

Coverage of the aortic segment longer than $200 \mathrm{~mm}$ was found to be an independent risk factor for SCI by Kotelis [7]. The median length of the covered aorta in group A was $205 \mathrm{~mm}$; however, the number of patients with a coverage of $>200 \mathrm{~mm}$ may be more important. In our population, only $33.9 \%(n=18)$ of patients had segments longer than $200 \mathrm{~mm}$ covered, which may partially explain our good results. Additionally, none of our patients had more than two elements implanted; only the implantation of more than three elements significantly increases the risk of paraplegia, according to the EUROSTAR investigators [22].

We did not observe the influence of prior abdominal aortic repair on an increased early rate of SCI in the covered-LSA nonrevascularised group. We had five patients with prior AAA surgery in the covered-LSA group, and none of them had SCI. However, all of these cases were elective. Czerny recently postulated that the coverage of two vascular territories in situations of hemodynamic instability may increase the chance of SCI [39]. The elective setting and no hemodynamic instability of these five cases may explain why no SCI occurred. Furthermore, hypogastric artery status would provide valuable additional insight into these cases; however, we have no such information in our case notes, hampering any conclusions.

Another factor playing a role in the explanation for the low SCI rate is that none of our patients of group A had renal insufficiency, which is known to be an independent risk factor $[7,22]$.

In the follow-up period, we recorded one case of paraplegia, which occurred in the seventh post-operative month. The paraplegia was due to spinal ischaemia with an ischemic focus at the level of T6-T8 and occurred in a patient who had an increased risk of early SCI based on the presence of one known risk factor (prior AAA open repair). In the follow-up CT, just before the occurrence of the paraplegia, a fresh type IA endoleak was found. We assume that, in this case, distal migration might have occurred (endoleak IA); the Adamkiewicz artery might have been occluded, resulting in paraplegia. The patient is ambulatory with crutches and is on a waiting list for proximal TEVAR extension.

Our results show that the implementation of a strategy of selective LSA revascularisation within a real-world, consecutive TEVAR population resulted in a low incidence of neurological complications. Low number of incidents did not allow to conduct a multivariate statistical analyses regarding SCI and CVA, which is a clear limitation of this study. Even if a relatively small sample size and heterogeneous pathology group may have biased our data, our per-procedure conclusions still stand.

However, we do foresee the necessity of further multicentre studies that report the combined morbidity of TEVAR with prophylactic LSA revascularisation vs. the morbidity of TEVAR without LSA revascularisation (preferably with all of the patients' data included on an intention-to-treat basis) as the next step in solving the on-going debate.

\section{Conclusion}

Our analysis, although retrospective and based on one institution experience, shows a realistic population of TEVAR patients. We prove that TEVAR with coverage of LSA origin can be accomplished with minimal neurological morbidity in this patient population. The study shows that LSA revascularisation is not mandatory before endograft deployment, especially in emergency settings. We also prove that although zone 2 TEVAR extends to the proximal landing zone, it does not prevent type IA endoleaks from appearing. A multicentre randomised control trial with higher number of patients is necessary for proper, robust conclusion to be established.

\section{Conflicts of interest None.}

Open Access This article is distributed under the terms of the Creative Commons Attribution License which permits any use, distribution, and reproduction in any medium, provided the original author(s) and the source are credited.

\section{References}

1. Stone DH, Brewster DC, Kwolek CJ, Lamuraglia GM, Conrad MF, Chung TK et al (2006) Stent-graft versus open-surgical repair of the thoracic aorta: mid-term results. J Vasc Surg 44(6):1188-1197

2. Bavaria JE, Appoo JJ, Makaroun MS, Verter J, Yu Z-F, Mitchell RS et al (2007) Endovascular stent grafting versus open surgical repair of descending thoracic aortic aneurysms in low-risk patients: a multicenter comparative trial. J Thorac Cardiovasc Surg 133(2):369-377

3. Gopaldas RR, Dao TK, LeMaire SA, Huh J, Coselli JS (2011) Endovascular versus open repair of ruptured descending thoracic aortic aneurysms: a nationwide risk-adjusted study of 923 patients. J Thorac Cardiovasc Surg 142(5):1010-1018

4. Goodney PP, Travis L, Lucas FL, Fillinger MF, Goodman DC, Cronenwett JL et al (2011) Survival after open versus endovascular 
thoracic aortic aneurysm repair in an observational study of the Medicare population. Circulation 124(24):2661-2669

5. Peterson BG, Eskandari MK, Gleason TG, Morasch MD (2006) Utility of left subclavian artery revascularization in association with endoluminal repair of acute and chronic thoracic aortic pathology. $\mathrm{J}$ Vasc Surg 43(3):433-439

6. Feezor RJ, Lee WA (2009) Management of the left subclavian artery during TEVAR. Semin Vasc Surg 22(3):159-164

7. Kotelis D, Geisbüsch P, Hinz U, Hyhlik-Dürr A, von Tengg-Kobligk $\mathrm{H}$, Allenberg JR et al (2009) Short and midterm results after left subclavian artery coverage during endovascular repair of the thoracic aorta. J Vasc Surg 50(6):1285-1292

8. Lombardi JV, Cambria RP, Nienaber CA, Chiesa R, Teebken O, Lee A et al (2012) Prospective multicenter clinical trial (STABLE) on the endovascular treatment of complicated type B aortic dissection using a composite device design. J Vasc Surg 55(3):629-640, e2

9. Steuer J, Eriksson MO, Nyman R, Björck M, Wanhainen A (2011) Early and long-term outcome after thoracic endovascular aortic repair (TEVAR) for acute complicated type B aortic dissection. Eur J Vasc Endovasc Surg 41(3):318-323

10. Matsumura JS, Lee WA, Mitchell RS, Farber MA, Murad MH, Lumsden AB et al (2009) The Society for Vascular Surgery practice guidelines: management of the left subclavian artery with thoracic endovascular aortic repair. J Vasc Surg 50(5):1155-1158

11. Weigang E, Parker JATC, Czerny M, Lonn L, Bonser RS, Carrel TP et al (2011) Should intentional endovascular stent-graft coverage of the left subclavian artery be preceded by prophylactic revascularisation? Eur J Cardiothorac Surg 40(4):858-868

12. Woo EY, Carpenter JP, Jackson BM, Pochettino A, Bavaria JE, Szeto WY et al (2008) Left subclavian artery coverage during thoracic endovascular aortic repair: a single-center experience. J Vasc Surg 48(3):555-560

13. Lee TC, Andersen ND, Williams JB, Bhattacharya SD, McCann RL, Hughes GC (2011) Results with a selective revascularization strategy for left subclavian artery coverage during thoracic endovascular aortic repair. Ann Thorac Surg 92(1):97-102, discussion102-3

14. Maldonado TS, Dexter D, Rockman CB, Veith FJ, Garg K, Arko F et al (2013) Left subclavian artery coverage during thoracic endovascular aortic aneurysm repair does not mandate revascularization. J Vasc Surg 57(1):116-124

15. Mitchell RS, Ishimaru S, Ehrlich MP, Iwase T, Lauterjung L, Shimono $T$ et al (2002) First International Summit on Thoracic Aortic Endografting: roundtable on thoracic aortic dissection as an indication for endografting. J Endovasc Ther 9(Suppl 2):II98-II105

16. Fillinger MF, Greenberg RK, McKinsey JF, Chaikof EL (2010) Reporting standards for thoracic endovascular aortic repair (TEVAR). J Vasc Surg 52(4):1022-1025

17. Ferrero E, Gibello L, Ferri M, Viazzo A, Nessi F (2013) Aortic arch rupture after multiple multilayer stent treatment of a thoracoabdominal aneurysm. J Vasc Surg S0741-5214(13):01518-8

18. Sepehripour AH, Ahmed K, Vecht JA, Anagnostakou V, Suliman A, Ashrafian $\mathrm{H}$ et al (2011) Management of the left subclavian artery during endovascular stent grafting for traumatic aortic injury-a systematic review. Eur J Vasc Endovasc Surg 41(6):758-769

19. Görich J, Asquan Y, Seifarth H, Krämer S, Kapfer X, Orend K-H et al (2002) Initial experience with intentional stent-graft coverage of the subclavian artery during endovascular thoracic aortic repairs. J Endovasc Ther 9(Suppl 2):II39-II43

20. Rehders TC, Petzsch M, Ince H, Kische S, Korber T, Koschyk DH et al (2004) Intentional occlusion of the left subclavian artery during stent-graft implantation in the thoracic aorta: risk and relevance. J Endovasc Ther 11(6):659-666

21. Riesenman PJ, Farber MA, Mendes RR, Marston WA, Fulton JJ, Keagy BA (2007) Coverage of the left subclavian artery during thoracic endovascular aortic repair. J Vasc Surg 45(1):90-94, discussion94-5

22. Buth J, Harris PL, Hobo R, van Eps R, Cuypers P, Duijm L et al (2007) Neurologic complications associated with endovascular repair of thoracic aortic pathology: incidence and risk factors. a study from the European Collaborators on Stent/Graft Techniques for Aortic Aneurysm Repair (EUROSTAR) registry. J Vasc Surg 46(6):1103-1110, discussion1110-1

23. Cooper DG, Walsh SR, Sadat U, Noorani A, Hayes PD, Boyle JR (2009) Neurological complications after left subclavian artery coverage during thoracic endovascular aortic repair: a systematic review and meta-analysis. J Vasc Surg 49(6):1594-601. http://www. sciencedirect.com/science/article/pii/S074152140802380X

24. Rizvi AZ, Murad MH, Fairman RM, Erwin PJ, Montori VM (2009) The effect of left subclavian artery coverage on morbidity and mortality in patients undergoing endovascular thoracic aortic interventions: a systematic review and meta-analysis. J Vasc Surg 50(5):1159-1169

25. Weigang E, Luehr M, Harloff A, Euringer W, Etz CD, Szabó G et al (2007) Incidence of neurological complications following overstenting of the left subclavian artery. Eur J Cardiothorac Surg 31(4):628-636

26. Cinà CS, Safar HA, Laganà A, Arena G, Clase CM (2002) Subclavian carotid transposition and bypass grafting: consecutive cohort study and systematic review. J Vasc Surg 35(3):422-429

27. Ozsvath KJ, Roddy SP, Darling RC, Byrne J, Kreienberg PB, Choi D et al (2003) Carotid-carotid crossover bypass: is it a durable procedure? J Vasc Surg 37(3):582-585

28. Bergeron P, Mangialardi N, Costa P, Coulon P, Douillez V, Serreo E et al (2006) Great vessel management for endovascular exclusion of aortic arch aneurysms and dissections. Eur J Vasc Endovasc Surg 32(1):38-45

29. Madenci AL, Keith Ozaki C, Belkin M, McPhee JT (2013) Carotidsubclavian bypass and subclavian-carotid transposition in the thoracic endovascular aortic repair era. J Vasc Surg 57(5):1275-1282, e2

30. Reece TB, Gazoni LM, Cherry KJ, Peeler BB, Dake M, Matsumoto $\mathrm{AH}$ et al (2007) Reevaluating the need for left subclavian artery revascularization with thoracic endovascular aortic repair. Ann Thorac Surg 84(4):1201-1205

31. Feezor RJ, Martin TD, Hess PJ, Klodell CT, Beaver TM, Huber TS et al (2007) Risk factors for perioperative stroke during thoracic endovascular aortic repairs (TEVAR). J Endovasc Ther 14(4):568-573

32. Chung J, Kasirajan K, Veeraswamy RK, Dodson TF, Salam AA, Chaikof EL et al (2011) Left subclavian artery coverage during thoracic endovascular aortic repair and risk of perioperative stroke or death. J Vasc Surg 54(4):979-984

33. Holt PJ, Johnson C, Hinchliffe RJ, Morgan R, Jahingiri M, Loftus IM et al (2010) Outcomes of the endovascular management of aortic arch aneurysm: implications for management of the left subclavian artery. J Vasc Surg 51(6):1329-1338

34. Gutsche JT, Cheung AT, McGarvey ML, Moser WG, Szeto W, Carpenter JP et al (2007) Risk factors for perioperative stroke after thoracic endovascular aortic repair. Ann Thorac Surg 84(4):11951200 , discussion 1200

35. Ullery BW, McGarvey M, Cheung AT, Fairman RM, Jackson BM, Woo EY et al (2012) Vascular distribution of stroke and its relationship to perioperative mortality and neurologic outcome after thoracic endovascular aortic repair. J Vasc Surg 56(6):1510-1517

36. Kotelis D, Bischoff MS, Jobst B, von Tengg-Kobligk H, Hinz U, Geisbüsch P et al (2012) Morphological risk factors of stroke during thoracic endovascular aortic repair. Langenbeck's Arch Surg 397(8): $1267-1273$

37. Melissano G, Tshomba Y, Bertoglio L, Rinaldi E, Chiesa R (2012) Analysis of Stroke after TEVAR Involving the Aortic Arch. Eur J Vasc Endovasc Surg 43(3):269-275

38. Bonati LH, Fraedrich G (2011) Trialists' Collaboration OBOTCS. Age modifies the relative risk of stenting versus endarterectomy for symptomatic carotid stenosis - a pooled analysis of EVA-3S, SPACE and ICSS. Eur J Vasc Endovasc Surg 41(2):153-158

39. Czerny M, Eggebrecht H, Sodeck G, Verzini F, Cao P, Maritati G et al (2012) Mechanisms of symptomatic spinal cord ischemia after TEVAR: insights from the European Registry of Endovascular Aortic Repair Complications (EuREC). J Endovasc Ther 19(1):37-43 